\title{
Characterization of Catalyst-Supported Dielectric Barrier Discharge Reactor
}

\author{
Shuiliang Yao*, Shin Yamamoto, Satoshi Kodama, Chieko Mine and Yuichi Fujioka
}

Chemical Research Group, Research Institute of Innovative Technology for the Earth, 9-2 Kizugawadai, Kizugawa-shi, Kyoto 619-0292, Japan

\begin{abstract}
The discharge properties and chemical reactions in plasma discharges using dielectric (alumina $\left.\mathrm{Al}_{2} \mathrm{O}_{3}\right)$ barrier discharge (DBD) reactors supported with $\mathrm{Fe}_{2} \mathrm{O}_{3}$ and $\mathrm{TiO}_{2}$ catalyst layers have been characterized. Ozone $\left(\mathrm{O}_{3}\right)$ was used as a probe substance to monitor the chemical reactions driven by plasma discharges. The light emission from discharge gaps of the catalyst-supported DBD reactors due to plasma discharges was evaluated, using a monochromator equipped with a high dynamic range streak camera. It has been found that the catalyst layers of $\mathrm{Fe}_{2} \mathrm{O}_{3}$ and $\mathrm{TiO}_{2}$ do not obviously influence plasma discharges and $\mathrm{O}_{3}$ generation. Light emission from the discharge gaps of the catalyst-supported DBD reactors is different possibly due to the difference in light absorption and scattering by catalyst layers. The mechanism of catalysis effect on $\mathrm{PM}$ oxidative removal over $\mathrm{Fe}_{2} \mathrm{O}_{3}$ has been proposed, where $\mathrm{Fe}_{2} \mathrm{O}_{3}$ layer has the highest light absorption effect compared with that of $\mathrm{TiO}_{2}$ and $\mathrm{Al}_{2} \mathrm{O}_{3}$.
\end{abstract}

Keywords: Transition metal oxide, Dielectric barrier discharge, Ozone generation, Light emission, PM oxidation.

\section{INTRODUCTION}

Plasma-catalysis chemical processes have been widely studied for decomposition of environmental pollutants, such as volatile organic compounds (VOC) and nitrogen dioxides (NOx, $x=1$ or 2) [1-13]. Many experimental results showed that such plasma-catalysis chemical processes have synergy effect in comparison with that when a plasma process and a catalysis process are used individually (such as [13]). In a plasma process, electric energy is injected into gases (background gases) in the discharge space, resulting in ionization, decomposition and excitation of the background gases. For example, $\mathrm{O}$ atoms can be generated from the decomposition of background gas $\mathrm{O}_{2}$ when electric energy is injected to $\mathrm{O}_{2}$ by applying an electric filed. $\mathrm{O}$ atoms are very reactive and can convert to ozone $\left(\mathrm{O}_{3}\right)$ via its combination reaction with $\mathrm{O}_{2}$. $\mathrm{O}$ atoms also react with low concentration hydrocarbons to yield $\mathrm{CO}$ and $\mathrm{CO}_{2}$, which is usually the mechanism of VOC removal in plasma discharges. If there is nitrogen monoxide (NO), $\mathrm{O}$ atoms and $\mathrm{O}_{3}$ can react with $\mathrm{NO}$ to give $\mathrm{NO}_{2}, \mathrm{NO}_{2}$ is easily removed by conversion to nitro hydrocarbon as reported by Dorai et al. [14, 15], or by selective catalytic reduction with ammonia or hydrocarbons $[16,17]$. As the most cases of VOC removals using plasma discharges are carried out in air atmosphere, $\mathrm{N}$ atoms can be generated as the most part of air is nitrogen $\left(\mathrm{N}_{2}\right)$. $\mathrm{N}$ atoms react with $\mathrm{NO}$ to give $\mathrm{N}_{2}$, indicating $\mathrm{NO}$ can be removed by reduction as suggested by many authors $[18,19]$. All those reactions occur in gaseous spaces inside or outside the discharge spaces. As the major fraction of the discharge energy is eventually converted to heat, only a small fraction of the discharge energy is used for production of reactive species [20]. On the other hand, when a catalyst is present in the discharge space, a part of the discharge energy can be used

*Address correspondence to this author at the Chemical Research Group, Research Institute of Innovative Technology for the Earth, 9-2 Kizugawadai, Kizugawa-shi, Kyoto 619-0292, Japan; E-mail: yao@rite.or.jp for heating catalyst. The plasma heated catalyst has effect on such as the decomposition of VOC. The plasma-produced reactive species promote the catalysis effect; however, the complicated gaseous and surface reactions happened in the plasma process make it difficult to be evaluated separately.

Recently, the authors developed a dielectric barrier discharge (DBD) reactor for diesel particulate matter (PM) removal [21-24]. The mechanism of PM removal is suggested to include two steps; the first step is the PM deposition (precipitation) due to plasma discharges, and the second step is the $\mathrm{PM}$ oxidation by oxygen $(\mathrm{O})$ atoms generated by plasma discharges. $\mathrm{O}_{3}$ and $\mathrm{NO}_{2}$ produced by plasma discharges also contribute PM oxidation [25]. Very recently, we found some transition metal oxides $\left(\mathrm{TiO}_{2}, \mathrm{ZnO}, \mathrm{V}_{2} \mathrm{O}_{5}, \mathrm{Fe}_{2} \mathrm{O}_{3}\right)$ that can be used as catalysts for diesel PM oxidation under plasma discharge conditions. From the correlation of the catalytic oxidation rates with the formation enthalpies per oxygen atom of the catalysts, the redox catalytic cycles have been found to act practically as the catalytic mechanisms of the transition metal oxides $[26,27]$. It has been suggested that $\mathrm{O}$ atoms generated by plasma discharges can play an important role in promoting the re-oxidation of metal under plasma discharge conditions. However, there is no experimental investigation to show the plasma discharges are not influenced by the supported catalyst layers on the surfaces of the dielectric barriers.

In this study, we characterize the DBD reactors supported with catalyst layers of $\mathrm{TiO}_{2}$ and $\mathrm{Fe}_{2} \mathrm{O}_{3}$ that have middle and highest effects on PM oxidation promotion. The plasmaproduced ozone $\left(\mathrm{O}_{3}\right)$ is used as a probe substance to monitor $\mathrm{O}$ atom formation. The light emission from the discharge gaps is measured. The mechanism of catalysis effect on PM oxidative removal is proposed.

\section{EXPERIMENTAL}

Fig. (1) shows the cross view of the DBD reactor. This DBD reactor consists of four alumina plates $\left(50 \times 50 \times 1 \mathrm{~mm}^{3}\right.$, 
$99.6 \%$ purity $)$, two alumina spacers $\left(10 \times 50 \times 0.5 \mathrm{~mm}^{3}\right)$ and two aluminum plate electrodes $\left(30 \times 30 \mathrm{~mm}^{2}\right)$. Alumina plates, alumina spacers, and aluminum plate electrodes were sandwiched closely. The alumina spacers were used to form a discharge space of $30 \times 30 \times 0.5 \mathrm{~mm}^{3}$ between two alumina plates; where the discharge gap is $0.5 \mathrm{~mm}$. $\mathrm{Fe}_{2} \mathrm{O}_{3}$ and $\mathrm{TiO}_{2}$ catalyst layers were coated on one surface of two alumina plates according to the method reported elsewhere [27]. The surfaces with catalyst layers were set facing to the discharge space. The DBD reactor was installed in an acrylic resin box (Fig. 2). Two kinds of assembly methods were used for ozone generation and light emission measurements. A plastic sheet was used to allow all of a gas mixture $\mathrm{O}_{2}$ and $\mathrm{N}_{2}$ passing through the discharge space when the DBD reactor was used for ozone generation measurement.

The characterization of the DBD reactor was carried using a discharge system shown in Fig. (3). This discharge system consists of a DBD reactor, a pulse power supply (DP$30 \mathrm{~K} 10$, Peec), a discharge voltage/current measuring system, and a monochromator (C-5094, Hamamatus) connected to a high dynamic range streak camera (C7700, Hamamatus). The pulse power supply was used to supply pre-trigger signals (11 ms before each voltage pulse) and positive pulse voltage to the DBD reactor. The pulse voltage was adjusted within a range of $0.5 \sim 15 \mathrm{kV}$ by changing the setup unit in the pulse power supply. The pulse repetition was fixed at $51 \mathrm{~Hz}$ for ozone generation measurement and at a single pulse mode for light emission measurement. The waveforms of discharge voltage and anode and cathode currents were measured using a voltage probe (V-P, P6015A, bandwidth DC $75 \mathrm{MHz}$, Tektronix) and two current transformers (CT1 and CT2, A6312, bandwidth DC 100MHz, Tektronix) with two current probe amplifiers (AM503B, Tektronix), respectively. The signals from the voltage probe and two current probe amplifiers were digitized and recorded using a digital phosphor oscilloscope (TDS 7104, bandwidth $1 \mathrm{GHz}$, Tektronix).

A gas mixture of $\mathrm{O}_{2}(99.9999 \%$ purity, $50 \mathrm{ml} / \mathrm{min})$ and $\mathrm{N}_{2}$ (99.9999\% purity, $\left.450 \mathrm{ml} / \mathrm{min}\right)$ was fed to the discharge space. $\mathrm{O}_{3}$ concentration in the gases from the output of the DBD reactor (Fig. 2a) was measured using a UV ozone analyzer (Model 620 MA-F, Ebara Jitsugyo).

The light emission from the discharge gap (Fig. 2b) over a single pulse discharge duration was measured optically using the monochromator, where a pulse voltage was applied to the DBD reactor at a single pulse mode. The monochromator was set at an entrance slit width of $50 \mu \mathrm{m}$, a grating of $300 \mathrm{gr} / \mathrm{mm}$ and a central wavelength of $380 \mathrm{~nm}$. The spectra were recorded using a streak camera (C7700, Hamamatsu) with the streak slit $(4.0 \mathrm{~mm})$ located in the image plane of the monochromator exit. The streak camera was controlled with a computer (PC), a signal generator (DG535, Stanford Research System), and the pre-trigger signal from the pulse power supply. The recording time of the streak camera was monitored using the digital phosphor oscilloscope. The spectra were analyzed using high performance digital temporal analyzer software (HPD-TA-6.1.0).

All discharge experiments were conducted at atmospheric pressure and room temperature $(298 \mathrm{~K})$ without heating except plasma discharge heating.

The power injection $P$ in kilowatts and energy injection $P_{a}$ in joules per pulse were calculated using Eqs. (1) and (2), respectively, over one pulse discharge duration. The discharge power in watts was defined as a product of $P_{a}$ and pulse repetition $(\mathrm{Hz})$.

$$
\begin{aligned}
& P=\frac{1}{1000} \sum_{i}\left(\frac{V_{i+1}+V_{i}}{2}\right)\left(\frac{I_{i+1}+I_{i}}{2}\right) \\
& P_{a}=\sum_{i}\left(\frac{V_{i+1}+V_{i}}{2}\right)\left(\frac{I_{i+1}+I_{i}}{2}\right)\left(t_{i+1}-t_{i}\right)
\end{aligned}
$$

where, $V_{i+1}$ and $V_{i}$, are discharge voltage in volts at discharge times $t_{i+1}$ and $t_{i}$ in seconds, respectively. $I_{i+1}$ and $I_{i}$ are currents in amperes at discharge times $t_{i+1}$ and $t_{i}$, respectively. The values of discharge voltage and currents were from the waveforms of discharge voltage and currents on HV side.

\section{RESULTS AND DISCUSSION}

\section{Typical Waveforms of Discharge Voltage and Current}

The typical waveforms of discharge voltage and current on the HV side are shown in Fig. (4). The positive pulse voltage is of a peak value: $13.4 \mathrm{kV}$, a rise-time (defined as the time when voltage rises from $10 \%$ to $90 \%$ of its peak value): $1.6 \mu \mathrm{s}$, and a pulse width (the time when the pulse voltage is kept over half of its peak value): $3.4 \mu$ s (Fig. 4a). The discharge current is in a range of $-0.37 \sim 0.80 \mathrm{~A}$. Here it must be noted that the current on the ground side is almost the same as that on the HV side (Fig. 4b).

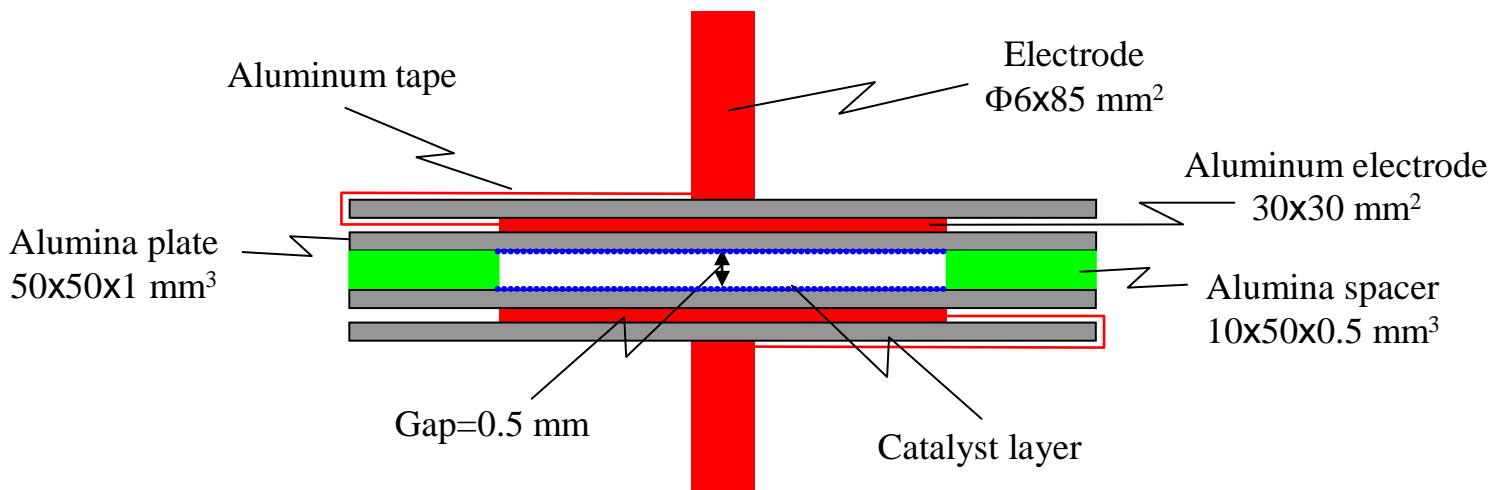

Fig. (1). Cross view of a DBD reactor. 
(a)
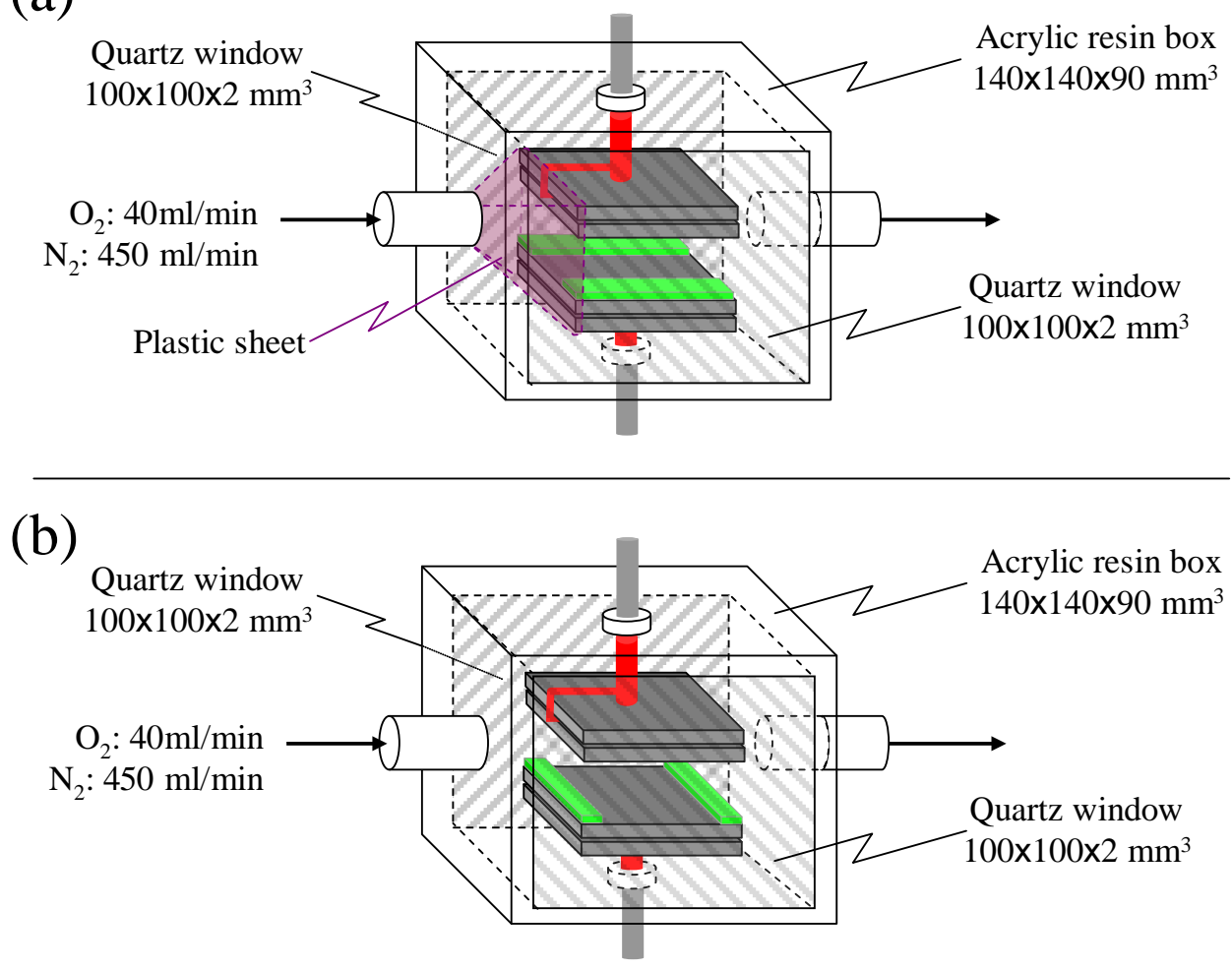

Fig. (2). Assembly view of the DBD reactor installed in an acrylic resin box. (a) For ozone generation measurement; (b) for light emission measurement.

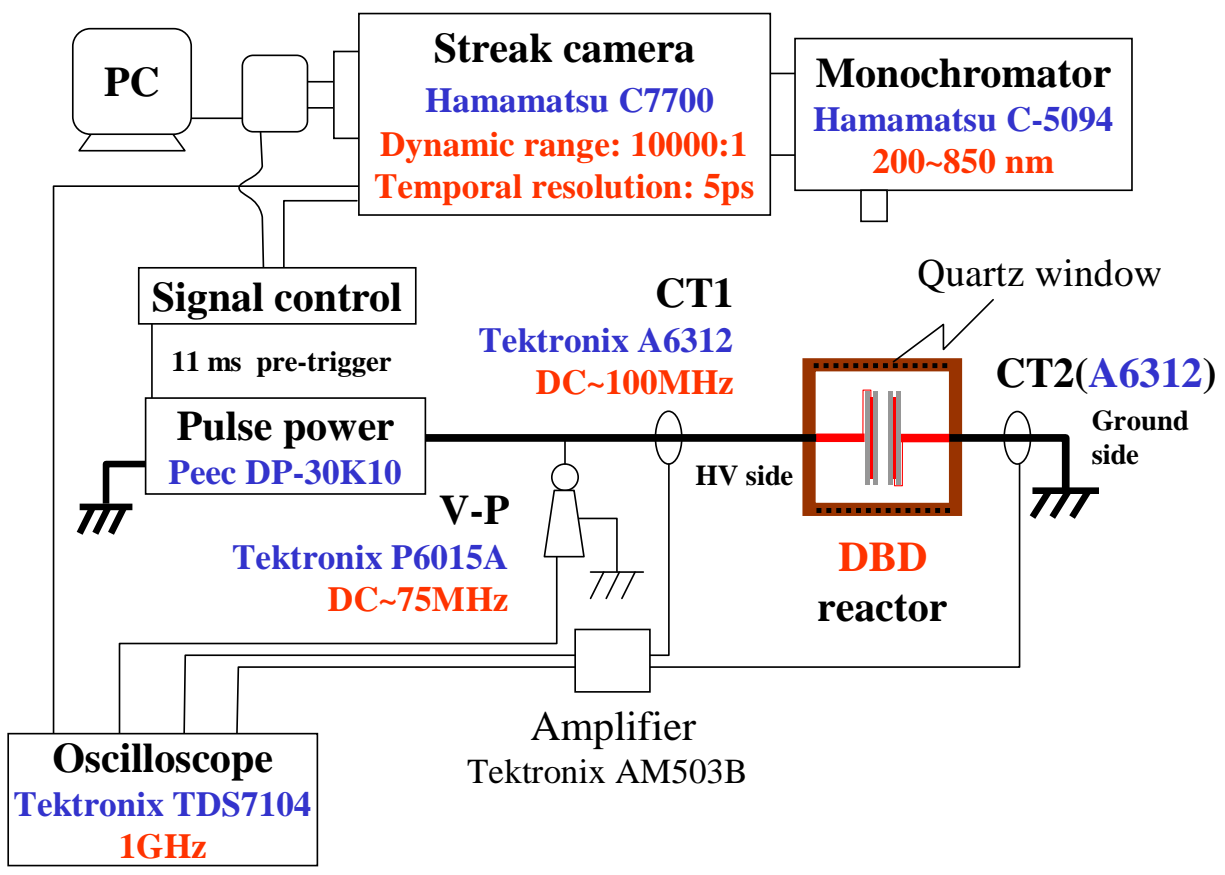

Fig. (3). Experimental setup for the characterization of DBD reactor.

The typical power injection and energy injection at various times are illustrated in Fig. (5). The power injection peaks to a level of $3.4 \mathrm{~kW}$ at $31.0 \mu \mathrm{s}$. The energy injection starts at time $30.0 \mu \mathrm{s}$ and increases to the peak of $4.35 \mathrm{~mJ}$ at time $32.3 \mu \mathrm{s}$ and decreases to a certain level of $2.53 \mathrm{~mJ}$ above $36 \mu$ s.
Inception Voltage for Plasma Discharges and Chemical Reactions

When the peak value of pulse voltage is high enough, plasma discharges occur in the background gases. The discharge power as a function of peak voltage is shown in Fig. (6). The discharge power increases with increasing peak 
voltage. There is no obvious difference when the DBD reactors supported without (None) or with $\mathrm{Fe}_{2} \mathrm{O}_{3}$ and $\mathrm{TiO}_{2}$ layers. This finding implied that the catalysts of $\mathrm{Fe}_{2} \mathrm{O}_{3}$ and $\mathrm{TiO}_{2}$ do not influence discharge power. The value of inception voltage for plasma discharges is $4.5 \mathrm{kV}$.

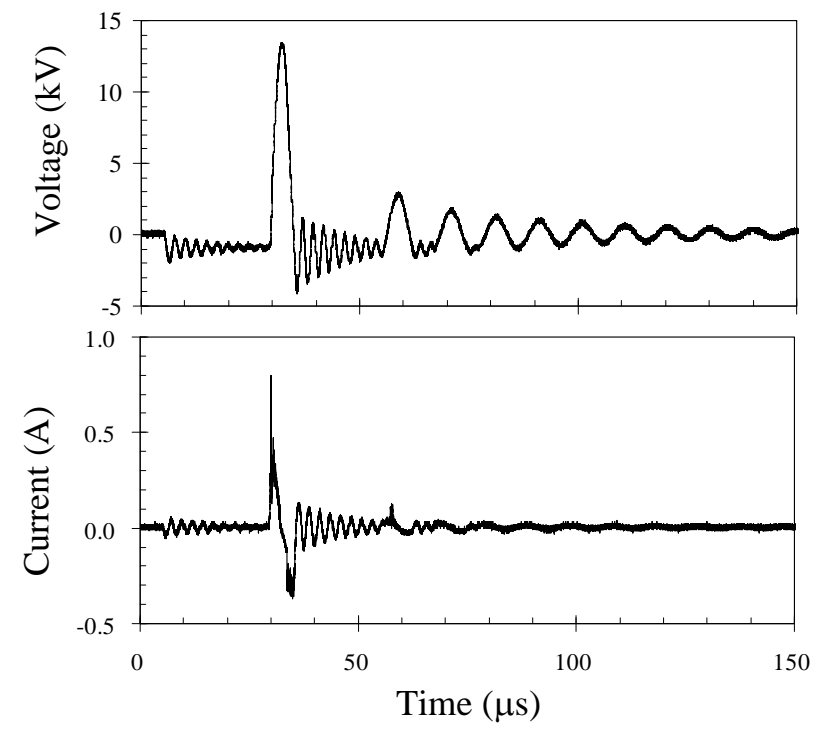

Fig. (4). Typical waveforms of discharge voltage and current.
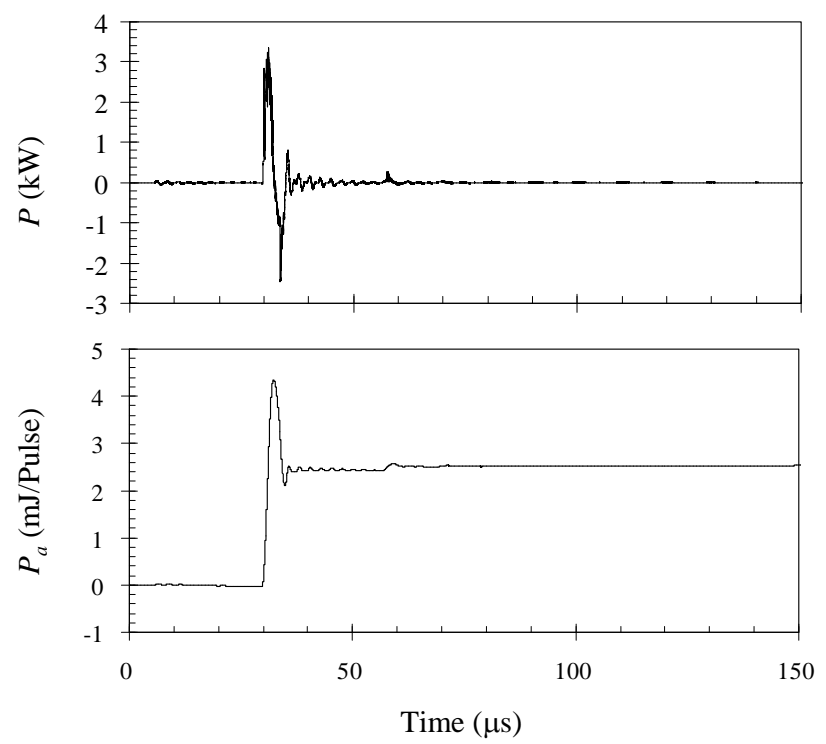

Fig. (5). Power injection $P$ and energy injection $P_{a}$ over one pulse discharge duration.

$\mathrm{O}_{3}$ concentrations as a function of peak voltage are shown in Fig. (7). $\mathrm{O}_{3}$ concentrations are zero below $4.5 \mathrm{kV}$, indicating that no plasma discharges occur, although the discharge power is not zero. $\mathrm{O}_{3}$ concentration increases with increasing peak voltage above $4.5 \mathrm{kV}$. The value of inception voltage for $\mathrm{O}_{3}$ formation is the same as that for plasma discharges. This finding implied that chemical reactions related with $\mathrm{O}$ formation from decomposition of $\mathrm{O}_{2}$ by impact with plasma-produced energized electrons occur within the gaseous phase as $\mathrm{O}_{3}$ is generally from combination of $\mathrm{O}$ with $\mathrm{O}_{2}$. The $\mathrm{O}_{3}$ concentration using the DBD reactors supported with $\mathrm{TiO}_{2}$ and $\mathrm{Fe}_{2} \mathrm{O}_{3}$ are higher than that supported without a catalyst (None) when the peak voltage is higher than $8 \mathrm{kV}$, although the differences among three DBD reactors are within error ranges.

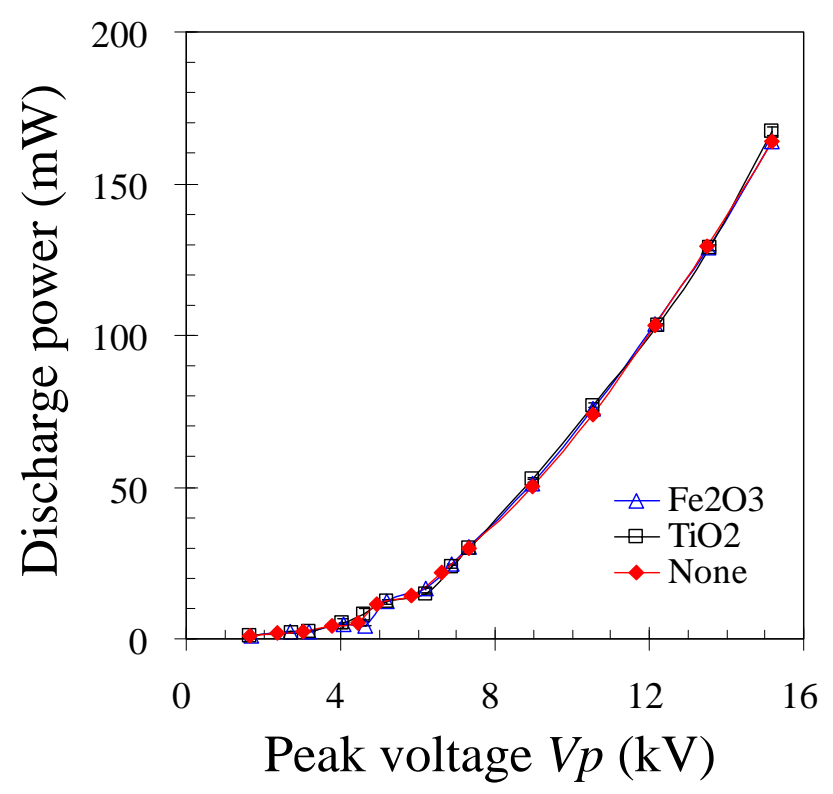

Fig. (6). Discharge power at various peak voltages.

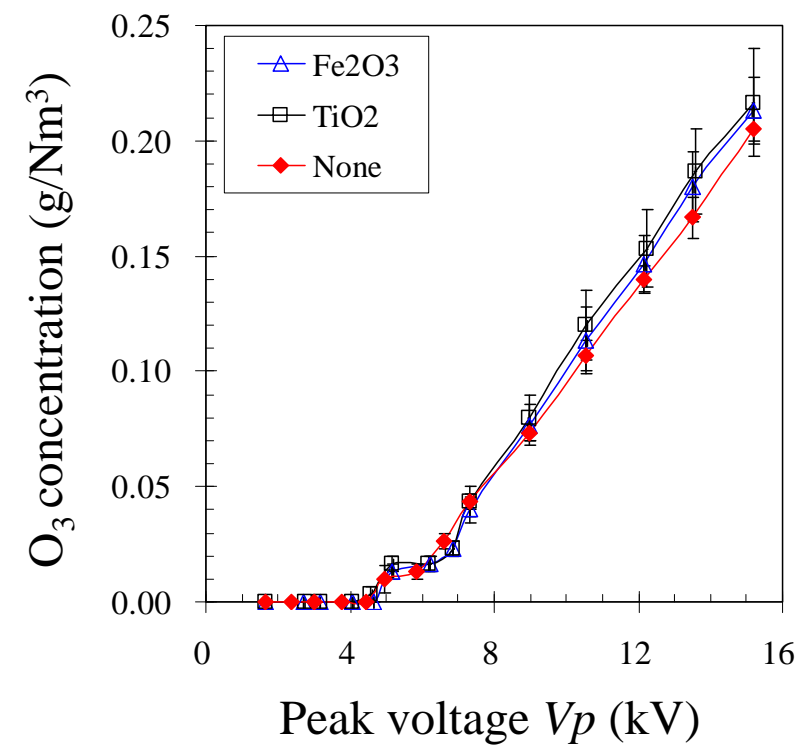

Fig. (7). $\mathrm{O}_{3}$ concentrations at various peak voltages.

\section{Light Emission}

The light emission was measured using the monochromator in a wavelength range of $200 \sim 850 \mathrm{~nm}$. It was found that detectable light is within $300 \sim 440 \mathrm{~nm}$. We then compared the intensities from the gaps of the DBD reactors without or with $\mathrm{TiO}_{2}$ and $\mathrm{Fe}_{2} \mathrm{O}_{3}$ catalyst layers, or with $\mathrm{SiO}_{2}$ layer, where $\mathrm{SiO}_{2}$ layer is used for fixing catalyst particles on its surface and from reaction of the water in air with perhydropolysilazane that is uniformly sprayed on alumina surface [27]. All light emission is due to the transitions of higherenergy states of nitrogen to their lower-energy states. The intensity from each gap is in an order of $\mathrm{TiO}_{2}>\mathrm{Al}_{2} \mathrm{O}_{3}$ 


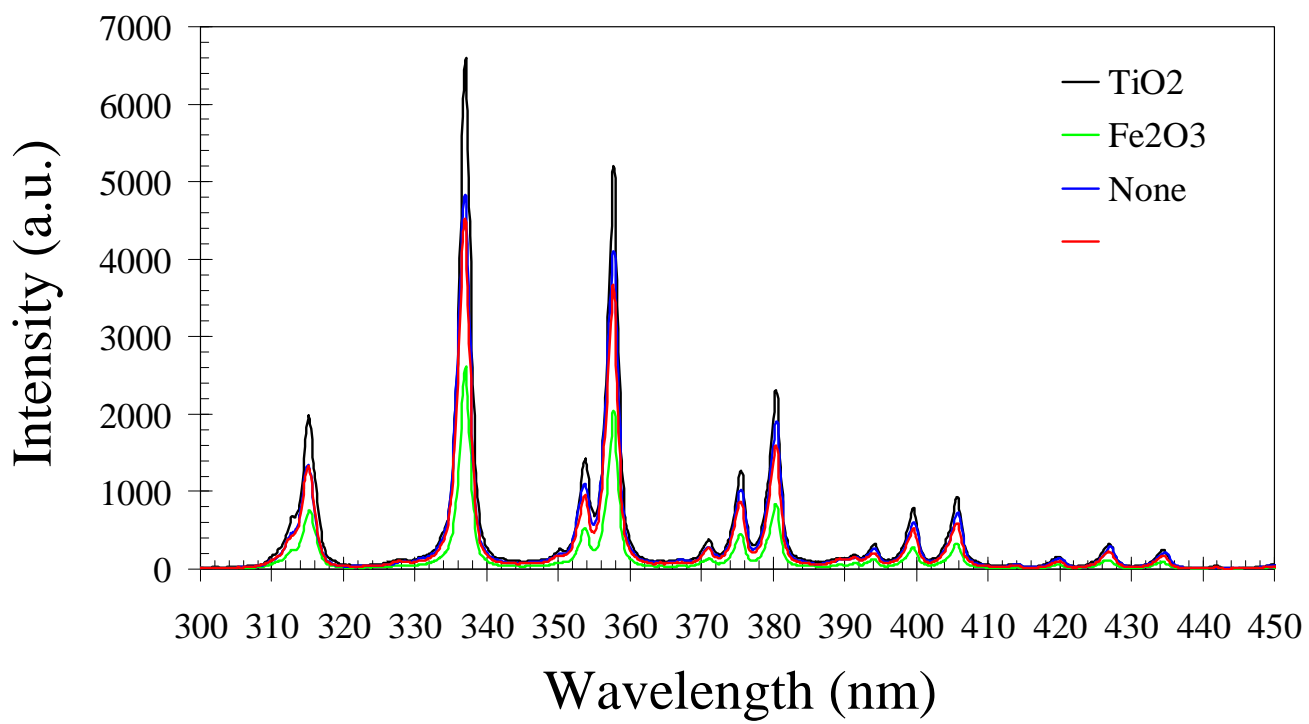

Fig. (8). Light emission intensities from each discharge gap. Experimental condition: single pulse discharge, peak voltage: $13.3 \mathrm{kV}$, energy injection: $2.9 \mathrm{~mJ} /$ pulse.

(None) $>\mathrm{SiO}_{2}>\mathrm{Fe}_{2} \mathrm{O}_{3}$. As the light emission from the discharge gaps includes the light generated by plasma discharges, or scattered and absorbed by catalyst layers, this difference in light emission is related with the light scattered and absorbed by catalyst layers as the discharges are same for each experiment. The red-brown $\mathrm{Fe}_{2} \mathrm{O}_{3}$ particles have the highest absorption effect on UV light, as the light intensity from the discharge gap with $\mathrm{Fe}_{2} \mathrm{O}_{3}$ layer is lowest. The light intensities from the discharge gaps with $\mathrm{TiO}_{2}$ layer and without catalyst layer (None) are higher than that with $\mathrm{SiO}_{2}$ layer; this is possibly due to the higher scattering effect of $\mathrm{TiO}_{2}$ and $\mathrm{Al}_{2} \mathrm{O}_{3}$ than $\mathrm{SiO}_{2}$, as $\mathrm{SiO}_{2}$ layer is very smoother than $\mathrm{TiO}_{2}$ and $\mathrm{Al}_{2} \mathrm{O}_{3}$ layers.

\section{General Comparison}

We then compared the catalysis effects on $\mathrm{O}_{3}$ formation, PM oxidation rates, and light emission from each gap. The comparison result is shown in Fig. (9), where PM oxidation rates are from [27]. $\mathrm{O}_{3}$ generation using the DBD reactors supported with $\mathrm{TiO}_{2}$ and $\mathrm{Fe}_{2} \mathrm{O}_{3}$ catalyst layers is improved by $12 \%$ and $8 \%$, respectively, in comparison with that using the DBD reactor without a catalyst (None). This difference may mainly come from the experiments as there is a maximum error about $11 \%$ in $\mathrm{O}_{3}$ concentration measurements. The light emission from the discharge gaps are different, which implied that catalysts have influence on light absorption and scattering, as the changes in the intensity of light

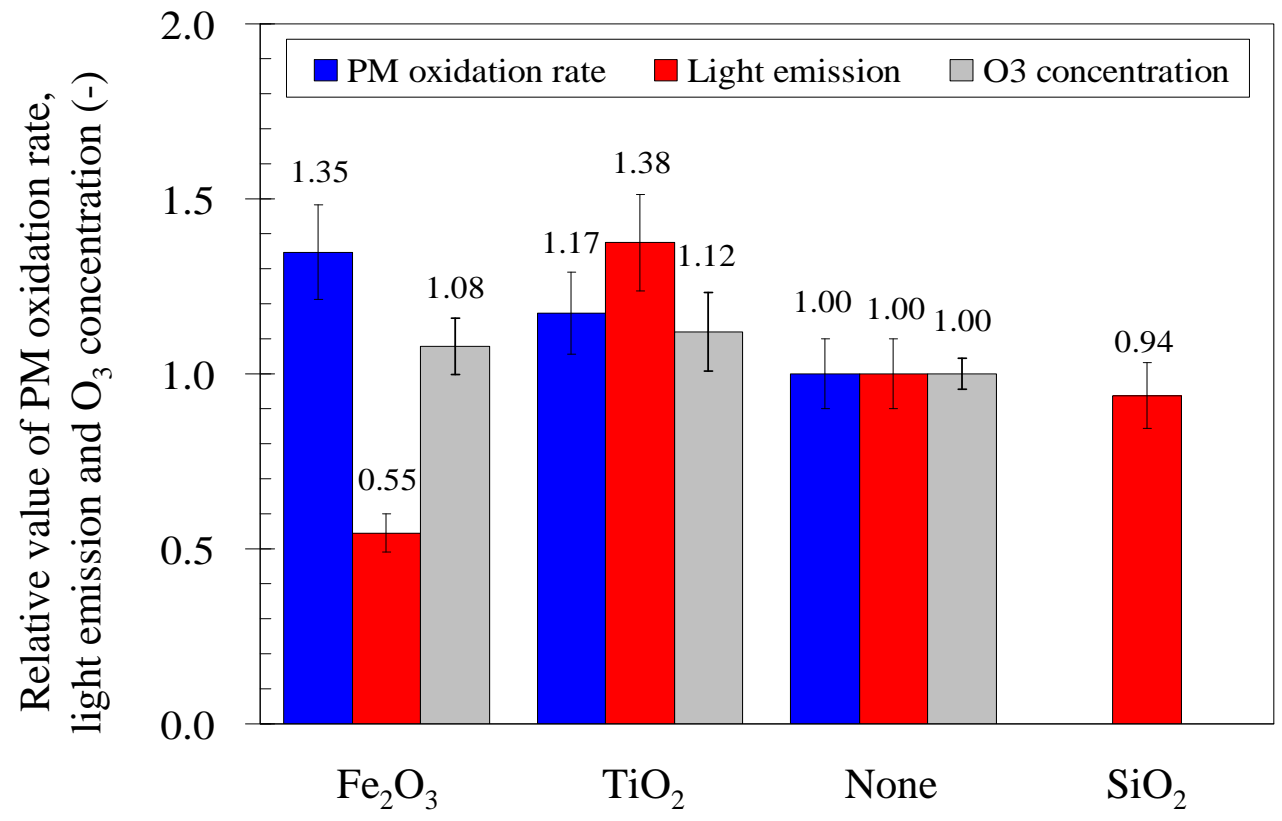

Fig. (9). Comparison of catalysis effect on $\mathrm{PM}$ oxidation rate, light emission (peak intensity at 337 nm wavelength) and $\mathrm{O}_{3}$ formation concentration. Experimental condition: $\mathrm{PM}$ oxidation rate: reactor temperature: $200{ }^{\circ} \mathrm{C}$, peak voltage $12 \mathrm{kV}$, pulse repetition $200 \mathrm{~Hz}$; $\mathrm{O}_{3}$ generation: peak voltage 13.5 13.6 kV, pulse repetition $51 \mathrm{~Hz}$; Light emission: as per Fig. (8). 


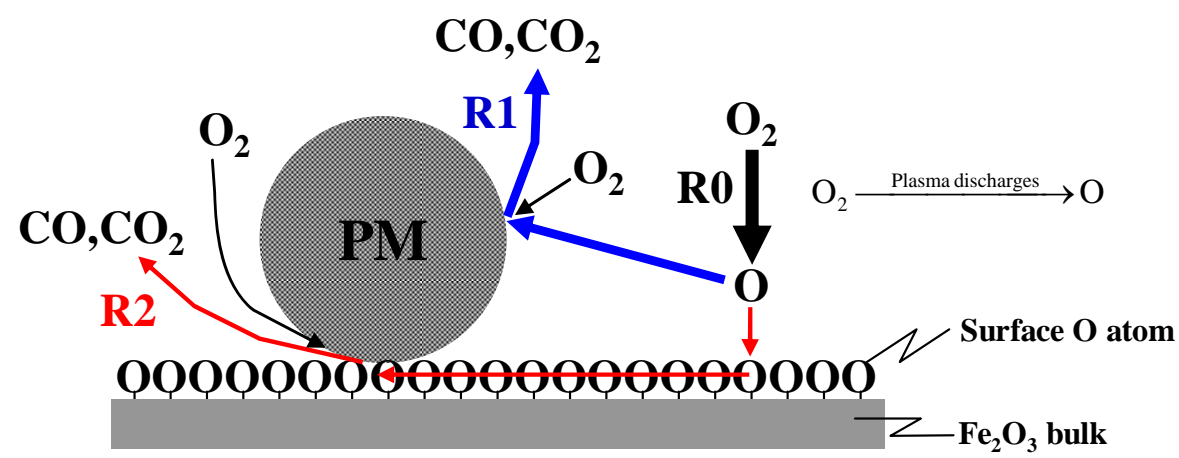

Fig. (10). The mechanism of $\mathrm{PM}$ or soot oxidation over $\mathrm{Fe}_{2} \mathrm{O}_{3}$ under plasma discharge conditions.

emission are due to the light absorption and scattering by surfaces surrounding the discharge space.

The catalytic mechanism of PM or soot oxidation over $\mathrm{Fe}_{2} \mathrm{O}_{3}$ have been reported following Mars and van Krevelen mechanism [28]. Fig. (10) shows the PM oxidation mechanism over $\mathrm{Fe}_{2} \mathrm{O}_{3}$ under plasma discharge conditions; where $\mathrm{O}_{2}$ is decomposed by plasma discharges to $\mathrm{O}$ atoms (R0). $\mathrm{PM}$ can be oxidized via gaseous $\mathrm{O}$ atoms and $\mathrm{O}_{2}$ to $\mathrm{CO}$ and $\mathrm{CO}_{2}$ (R1). PM oxidation is promoted by $\mathrm{O}$ atoms that transport on $\mathrm{Fe}_{2} \mathrm{O}_{3}$ surface via $\mathrm{R} 2$, where $\mathrm{O}$ atoms on $\mathrm{Fe}_{2} \mathrm{O}_{3}$ surface are supplemented by $\mathrm{O}$ atoms produced by plasma discharges and consumed by reaction with PM. From the fact that the $\mathrm{PM}$ oxidation rate over $\mathrm{Fe}_{2} \mathrm{O}_{3}$ is 1.35 times of that over $\mathrm{Al}_{2} \mathrm{O}_{3}$ (None), the major fraction $74 \%\left(=\frac{1}{1.35} \times 100 \%\right)$ of $\mathrm{PM}$ is removed via $\mathrm{R} 1$, a small fraction $26 \%$ ( $\left.=\frac{1.35-1}{1.35} \times 100 \%\right)$ of PM is removed via $\mathrm{R} 2$. As the $\mathrm{Fe}_{2} \mathrm{O}_{3}$ has no catalytic effect on $\mathrm{PM}$ oxidation at $300{ }^{\circ} \mathrm{C}$ without plasma discharges [28], the increase in $\mathrm{PM}$ oxidation rate with $\mathrm{Fe}_{2} \mathrm{O}_{3}$ layer implied that $\mathrm{Fe}_{2} \mathrm{O}_{3}$ layer on $\mathrm{Al}_{2} \mathrm{O}_{3}$ surface has synergy effect on promotion of PM oxidation under plasma discharge conditions.

\section{CONCLUSION}

The discharge properties and chemical reactions in plasma discharges using the DBD reactors supported with $\mathrm{Fe}_{2} \mathrm{O}_{3}$ and $\mathrm{TiO}_{2}$ catalyst layers have been investigated. The main conclusions are summarized as follows:

1. The catalyst layers of $\mathrm{Fe}_{2} \mathrm{O}_{3}$ and $\mathrm{TiO}_{2}$ supported on $\mathrm{Al}_{2} \mathrm{O}_{3}$ surfaces within the DBD reactor do not obviously influence plasma discharges. The same discharge power can be obtained if the same voltage is applied to the catalyst-supported DBD reactors.

2. $\mathrm{O}_{3}$ generation using the catalyst-supported DBD reactors has a little influence by $\mathrm{Fe}_{2} \mathrm{O}_{3}$ and $\mathrm{TiO}_{2}$ layers, but within the error range.

3. Light emission from the discharge gaps of the catalyst-supported DBD reactors is different as catalyst layers absorb and scatter the light. $\mathrm{Fe}_{2} \mathrm{O}_{3}$ layer has the highest light absorption effect compared with that of $\mathrm{TiO}_{2}$ and $\mathrm{Al}_{2} \mathrm{O}_{3}$ (None) layers.

4. $\mathrm{Fe}_{2} \mathrm{O}_{3}$ layer on $\mathrm{Al}_{2} \mathrm{O}_{3}$ surface has synergy effect on promotion of PM oxidation under plasma discharge conditions. $\mathrm{PM}$ oxidation is promoted by $\mathrm{O}$ atoms on
$\mathrm{Fe}_{2} \mathrm{O}_{3}$ surface; where $\mathrm{O}$ atoms on $\mathrm{Fe}_{2} \mathrm{O}_{3}$ surface are supplemented by $\mathrm{O}$ atoms in plasma space produced by plasma discharges and consumed by reaction with PM.

\section{ACKNOWLEDGEMENTS}

This work was supported by the New Energy Industrial Technology Development Organization (NEDO) under a government fund from the Ministry of Economy, Trade and Industry, Japan. Prof. Y. Nihei at Tokyo University of Science is grateful for helpful advice.

\section{REFERENCES}

[1] Kameoka, S.; Kuriyama, T.; Kuroda, M.; Ito, S.; Kurimori, K. The chemical interaction between plasma-excited nitrogen and the surface of titanium dioxide. Appl. Surf. Sci., 1995, 89, 411-415.

[2] Bröer, S.; Hammer, T. Selective catalytic reduction of nitrogen oxides by combining a non-thermal plasma and a $\mathrm{V}_{2} \mathrm{O}_{5}-\mathrm{WO}_{3} / \mathrm{TiO}_{2}$ catalyst. Appl. Catal. B : Environ., 2000, 28, 101-111.

[3] Kim, H.H.; Takashima, K.; Katsura, S.; Mizuno, A. Lowtemperature NOx reduction processes using combined systems of pulsed corona discharge and catalysts J. Phys. D: Appl. Phys., 2001, 34, 604-613.

[4] Krawczyk, K.; Mlotek, M. Combined plasma-catalytic processing of nitrous oxide. Appl. Catal. B: Environ., 2001, 30, 233-245.

[5] Roland, U.; Holzer, F.; Kopinke, F.D. Improved oxidation of air pollutants in a non-thermal plasma, Catal. Today, 2002, 73, 315323.

[6] Ogata, A.; Einaga, H.; Kabashima, H.; Futamura, S.; Kushiyama, S.; Kim, H.H. Effective combination of nonthermal plasma and catalysts for decomposition of benzene in air. Appl. Catal. B: Environ., 2003, 46, 87-95.

[7] Lee, B.Y.; Park, S.H.; Lee, S.C.; Kang, M.; Choung, S. J. Decomposition of benzene by using a discharge plasma-photocatalyst hybrid system. Catal. Today, 2004, 93, 769-776.

[8] Dors, M.; Mizeraczyk, J. NOx removal from a flue gas in a corona discharge-catalyst hybrid system. Catal. Today, 2004, 89, 127-133.

[9] Futamura, S.; Einaga, H.; Kabashima, H.; Hwan, L.Y. Synergistic effect of silent discharge plasma and catalysts on benzene decomposition. Catal. Today, 2004, 89, 89-95.

[10] Hammer, T.; Kappes, T.; Baldauf, M. Plasma catalytic hybrid processes: gas discharge initiation and plasma activation of catalytic processes. Catal. Today, 2004, 89, 5-14.

[11] Thevenet, F.; Guaïtella, O.; Herrmann, J. M.; Rousseau, A.; Guillard, C. Photocatalytic degradation of acetylene over various titanium dioxide-based photocatalysts. Appl. Catal. B: Environ., 2005, 61, 58-68.

[12] Lu, B.; Zhang, X.; Yu, X.; Feng, T.; Yao, S. Catalytic oxidation of benzene using DBD corona discharges. J. Hazard. Mater., 2006, 137(1), 633-637.

[13] Thevenet, F.; Guaitella, O.; Guillard, C.; Puzenat, E.; Stancu, G.; Roepcke, J.; Rousseau, A. Comparison of the plasma-photocatalyst synergy at low and atmospheric pressure. Int. J. Plasma Environ. Sci. Technol., 2007, l(1), 52-56. 
[14] Dorai, R.; Kushner, M.J. Consequences of propene and propane on plasma remediation of NOx. J. Appl. Phys., 2000, 88(6), 37393747.

[15] Dorai, R.; Kushner, M.J. Repetitively pulsed plasma remediation of NOx in soot laden exhaust using dielectric barrier discharges. $J$. Phys. D: Appl. Phys., 2002, 35, 2954-2968.

[16] Schwidder, M.; Heikens, S.; Toni, A. De; Geisler, S.; Berndt, M.; Brückner, A.; Grünert, W. The role of NO2 in the selective catalytic reduction of nitrogen oxides over Fe-ZSM-5 catalysts: active sites for the conversion of $\mathrm{NO}$ and NO/NO2 mixtures. J. Catal., 2008, 259(1), 96-103.

[17] Miessner, H.; Francke, K.P.; Rudolph, R.; Hammer, T. NOx removal in excess oxygen by plasma-enhanced selective catalytic reduction. Catal. Today, 2002, 75(1-4), 325-330.

[18] Penetrante, B.M.; Hisao, M.C.; Merritt, B.T.; Vogtlin, G.E.; Wallman, P.H. Comparison of electrical discharge techniques for nonthermal plasma processing of $\mathrm{NO}$ in $\mathrm{N}_{2}$. IEEE Trans. Plasma Sci., 1995, 23(4), 679-687.

[19] Yoon, S.; Panov, A.G.; Tonkyn, R.G.; Ebeling, A.C.; Barlow, S.E.; Balmer, M.L. An examination of the role of plasma treatment for lean $\mathrm{NO}_{x}$ reduction over sodium zeolite $\mathrm{Y}$ and gamma alumina Part 2: Formation of nitrogen. Catal. Today, 2002, 72(3-4), 251-257.

[20] Elliason B.; Kogelschatz U. Modeling and applications of silent discharge plasmas. IEEE Trans. Plasma Sci., 1991, 19(2), 309-323.

[21] Yao, S.; Fushimi, C.; Madokoro, K.; Yamada, K. Uneven dielectric barrier discharge reactors for diesel particulate matter removal. Plasma Chem. Plasma Process., 2006, 26, 481-493.
[22] Yao, S.; Madokoro, K.; Fushimi, C.; Fujioka, Y. Experimental investigation on diesel PM removal using uneven DBD reactors. AIChE J., 2007, 53(7), 1891-1897.

[23] Fushimi, C.; Madokoro, K.; Yao, S.; Fujioka, Y.; Yamada, K. Influence of polarity and rise time of pulse voltage waveforms on diesel particulate matter removal using an uneven dielectric barrier discharge reactor. Plasma Chem. Plasma Process., 2008, 28(4), 511-522.

[24] Kodama, S.; Yao, S.; Yamamoto, S.; Mine, C.; Fujioka, Y. Oxidization mechanism of diesel particulate matter in plasma discharges. Chem. Lett., 2009, 38, 50-51.

[25] Yao, S.; Mine, C.; Fushimi, C.; Madokoro, K.; Kodama, S.; Yamamoto, S.; Fujioka, Y.; Kim, Y.-H.; Naito, K.; Fujikawa, H.; Ogawa, T.; Tan, I.; Hasegawa, K.; Tanaka, H. Basic study of PM oxidation promoted by $\mathrm{O}_{3}$ and $\mathrm{NO}_{2}$. Trans. Soc. Autom. Eng. Jpn., 2008, 39(2), 387-392.

[26] Yamamoto, S.; Yao, S.; Kodama, S.; Mine, C.; Fujioka, Y. Effects of $\mathrm{O}_{3}$ and $\mathrm{NO}_{2}$ on catalytic oxidation of diesel PM. Chem. Lett., 2008, 37(9), 998-999.

[27] Yamamoto, S.; Yao, S.; Kodama, S.; Mine, C.; Fujioka, Y. Investigation of transition metal oxide catalysts for diesel PM removal under plasma discharge conditions. Open Catal. J., 2008, 1, 11-16.

[28] Mul, G.; Kapteijn, F.; Doornkamp, C.; Moulijn, J. A. Transition metal oxide catalyzed carbon black oxidation: a study with ${ }^{18} \mathrm{O}_{2} . J$. Catal., 1998, 179, 258-266.

(C) Yao et al.; Licensee Bentham Open.

This is an open access article licensed under the terms of the Creative Commons Attribution Non-Commercial License (http://creativecommons.org/licenses/by$\mathrm{nc} / 3.0 /$ ) which permits unrestricted, non-commercial use, distribution and reproduction in any medium, provided the work is properly cited. 